\title{
Morphology, Hardness, and Wear Properties of Ni-Base Composite Coating Containing Al Particle
}

\author{
Rouhollah Mousavi ${ }^{1, *}$, Flavio Deflorian ${ }^{2}$ and Mohammad Ebrahim Bahrololoom ${ }^{3}$ \\ 1 Department of Materials Science and Engineering, Faculty of Engineering, Shahid Chamran University of \\ Ahvaz, Ahvaz 61357-831351, Iran \\ 2 Department of Industrial Engineering, University of Trento, via Sommarive 9, 38123 Trento, Italy; \\ flavio.deflorian@unitn.it \\ 3 Department of Materials Science and Engineering, Shiraz University, Shiraz 71964-84334, Iran; \\ bahrolom@shirazu.ac.ir \\ * Correspondence: mousavi@scu.ac.ir
}

Received: 1 January 2020; Accepted: 29 March 2020; Published: 2 April 2020

check for updates

\begin{abstract}
Ni}-\mathrm{Mo} / \mathrm{Al}$ composite coatings were obtained by electrodeposition from a Ni-Mo plating bath containing suspended Al particles. The factors including temperature, current density, and stirring rate affecting coating composition, wear, roughness, and morphology have been studied. It was found that properties such as hardness, roughness, wear, and the Al particle content showed parabolic behavior when changing each parameter. That means that there is a critical value for the mentioned parameters at which the properties of coatings become maximal.
\end{abstract}

Keywords: composite coating; parabolic behavior; chemical composition; morphology; electrodeposition parameter

\section{Introduction}

Electroplating baths containing micron and sub-micron particles are used to make composite coatings. Variable amounts of these particles are deposited on the cathode surface by Faraday and electrophoretic mechanisms [1].

In the field of electrochemistry, for the single-step-production of completely dense materials, the absence of extraneous porosity, and reproducibility, have been considered outstanding characteristics [2]. Production of coatings by electrodeposition is cheap and easily done [2,3]. The structures and chemical compositions of composite coatings are not only affected by the concentration, size, distribution, and nature of the reinforcing particles, but are also powerfully affected by the operating features of electrodeposition, such as current density, stirring rate, temperature, and amount of particles in the solution [4]. By changing each parameter, it is possible to obtain a coating with different properties.

There are many reports which show that the amount of particles in a deposit reaches a maximum at a certain temperature; at a higher temperature, the amount decreases [5-10]. Shi et al. [6] demonstrated that the amount of deposited particles increases by increasing the temperature up to $40^{\circ} \mathrm{C}$, and then decreases by further increasing temperature. Many researchers demonstrated that deposited particle content is increased up to a maximum and then decreases with increasing current density [6,7,11-14]. Shi et al. [6], Vaezi et al. [7], Baghery et al. [11], and Daemi et al. [14] found and reported particle content reaches a maximum and then decreases by increasing current density. Among all the parameters, bath agitation during the electrodeposition of a composite coating is particularly important. During electrodeposition, bath agitation helps to maintain the particles suspended in the electrolyte and transports the particles to the cathode surface by convective-diffusion. It seems that the incorporation 
of particles in the coating becomes high if the stirring rate is sufficiently high. As seen in the literature [15-17], the amount of deposited particles is increased up to a maximum value and then decreased by further increasing the stirring rate, regardless of the values of the current density and the temperature. Consequently, an operational parameter describing the electroplating bath's composition or process conditions can have a positive or negative effect on the particle content of the deposited composite coating.

As mentioned above, there is a critical value for each parameter, beyond which the effect of each parameter on the included particle content of the deposit becomes the opposite. In this work, the effects of some operating parameters, such as current density, temperature, and stirring rate, on some properties of a Ni-base composite coating containing Al particles were investigated.

\section{Materials and Methods}

Electroplating baths were prepared by dissolving high purity chemicals in twice distilled water. The bath's chemical composition and operating parameters have been presented in Table 1 . The $\mathrm{pH}$ of solutions was regulated at 4 with sulfuric acid and sodium hydroxide solutions.

Table 1. The bath's chemical composition, and operating parameters and their values.

\begin{tabular}{cc}
\hline Parameter & Levels \\
\hline Trisodium Citrate $(\mathrm{M})$ & 0.3 \\
Temperature $\left({ }^{\circ} \mathrm{C}\right)$ & $25,40,50,60$ \\
Nickel Sulphate $(\mathrm{M})$ & 0.35 \\
Sodium Molybdate $(\mathrm{M})$ & 0.01 \\
Al Content $(\mathrm{g} / \mathrm{L})$ & 5 \\
CTAB $(\mathrm{g} / \mathrm{L})$ & 0.3 \\
SDS $(\mathrm{g} / \mathrm{L})$ & 0.5 \\
Stirring Rate $(\mathrm{rpm})$ & $350,500,650,800$ \\
Current Density $\left(\mathrm{mA} / \mathrm{cm}^{2}\right)$ & $15,30,50,60$ \\
pH & 4 \\
\hline
\end{tabular}

Plain carbon steel and a piece of pure nickel metal were used for the anode and cathode, respectively. The surface area of the cathode was $1 \mathrm{~cm}^{2}$. All surfaces of the substrate except one surface were covered with a non-conducting epoxy resin. The anode and cathode were kept at a constant distance from each other.

Before each deposition, the working electrode was sanded with emery paper 80, 120, 240, 360, 600, 800 , and 1200 . The substrate, after being mechanically polished, was electrically polished in $95 \mathrm{vol} . \%$ acetic acid $+5 \mathrm{vol} . \%$ perchloric acid for $3 \mathrm{~min}$. At last, before electrodeposition, the prepared surface was activated in dilute sulfuric acid for $20 \mathrm{~s}$. In the process between each step, distilled water was used to wash the specimens. Electrodeposition was done in a $250 \mathrm{~mL}$ glass beaker. The electrodes were placed horizontally parallel to each other in the beaker containing the bath solution. (The working electrode was placed under the anode). To completely cover the surface of particles with surfactant, particles were firstly added into a low volume of bath solution containing surfactant and stirred solution for $1 \mathrm{~h}$. Then, the volume of the mentioned solution was increased up to $200 \mathrm{~mL}$. Afterward, the whole solution was stirred ultrasonically for $70 \mathrm{~min}$ for mixing before deposition. To keep the particles suspended in the plating solution, the bath was stirred continuously by a magnetic stirrer.

An Environmental Scanning Electron Microscope (ESEM XL30, Philips, Eindhoven, Netherlands) was used to investigate the coating morphology. The chemical composition of the coating was also detected by energy dispersive spectrometry (EDS). Phases of coatings were identified by $\mathrm{X}$-Ray Diffraction (XRD, PanAlytical X'pert, Eindhoven, Netherlands) using X-ray $\mathrm{Cu} \mathrm{K} \alpha$ radiation $(\lambda=1.5406 \AA)$. 
The grain size of the coating was obtained by using the Shearer equation by measuring the full-width at half maximum (FWHM) of the (111) and (200) peaks. The Scherrer equation is written as follows:

$$
D=\frac{0.9 \times \lambda}{\beta \times \cos \alpha}
$$

In this equation, $D$ is grain size (nm), $\lambda$ is wave length of diffracted $X$-ray, $\alpha$ is the Brag angle, and $\beta$ is the FWHM. The four-parameter Gaussian function was used for curve fitting analysis required for FWHM determination. This equation is written as follows:

The hardness number reported for each coating is the average of three hardness values obtained from different points of the coating surface. The Vickers diamond pyramid indenter is in the shape of a squared pyramid with an angle of $136^{\circ}$ between faces. To estimate the hardness number of Vickers diamond pyramid (HV), both diagonals of the indentation were calculated, and the mean of these values along with the load was considered to identify the amount of HV.

To measure the wear resistance of the coatings, a pin-on-disc machine (POD) under unlubricated conditions was used. All wear tests were performed at room temperature and in air. The steel rod pin was chrome-plated and $6 \mathrm{~mm}$ in diameter with a hemispherical tip. Before each test, the coated sample and pin were weighed with an accuracy of $0.1 \mathrm{mg}$. After that, they were mounted to their proper locations in the wear apparatus so that the pin was vertically above the horizontal sample touching its surface. The wear test was performed for a distance of $180 \mathrm{~m}$. In all tests, the pin rotational speed was kept constant at $0.03 \mathrm{~m} / \mathrm{s}$. The wear test was performed under a constant load of $300 \mathrm{gf}$. After doing the wear test, the coated sample was weighed. The difference between its weight before and after each test was taken as a factor for its wear behavior.

If the density of coatings obeys the mixture law, the volumetric wear rate (VWR) can be obtained from Equation (2).

$$
\operatorname{VWR}\left(\mathrm{m}^{3} /(\mathrm{N} \cdot \mathrm{m})\right)=m /\left(\rho_{\text {composite }} \times F \times L\right)
$$

where $m$ is the average mass loss $(\mathrm{g}), F$ is the force applied $(\mathrm{N}), L$ is the sliding distance $(\mathrm{m})$, and $\rho$ is the density of the materials $\left(\mathrm{g} / \mathrm{m}^{3}\right)$.

$$
1 /\left(\rho_{\text {composite }}\right)=X_{\mathrm{Ni}} / \rho_{\mathrm{Ni}}+X_{\mathrm{Mo}} / \rho_{\mathrm{Mo}}+X_{\mathrm{Al}} / \rho_{\mathrm{Al}}
$$

where $X_{\mathrm{i}}$ is the weight fraction of $\mathrm{i}$ component in the coating. $\rho_{\mathrm{Ni}}, \rho_{\mathrm{Mo}}$ and $\rho_{\mathrm{Al}}$ are taken as 8.9, 10.2, and $2.7 \mathrm{~g} / \mathrm{cm}^{3}$, respectively.

The pin weight change was not very noticeable and was neglected in the wear rate calculations, and therefore, not reported here.

The roughness average $\left(R_{\mathrm{a}}\right)$ was applied to measure the surface roughness in this study. In the current examination, the concept of surface roughness was concentrated on the universally identified $R_{\mathrm{a}}$, which has been the most popular international parameter of roughness. The roughness measurement of the composite coatings was carried out two times using a Mitutoyo roughness testing instrument, and the average of them was reported as the final roughness number.

\section{Results and Discussion}

\subsection{Temperature Effect}

As Figure 1 shows, the $\mathrm{Al}$ content is decreased when the temperature increases beyond $40{ }^{\circ} \mathrm{C}$. The decreasing trend after a critical temperature value may also be due to the decrease in the current efficiency of nickel deposition at higher temperatures. The curve has a Gaussian form like the curve of $\mathrm{Al}$ with a maximum temperature at $40^{\circ} \mathrm{C}$. Raising the temperature typically lowers the polarization, reduces the concentration of metal in the cathode diffusion layer, and may influence the cathode current effectiveness of the deposition of metals, especially those deposited from complex ions [18]. 


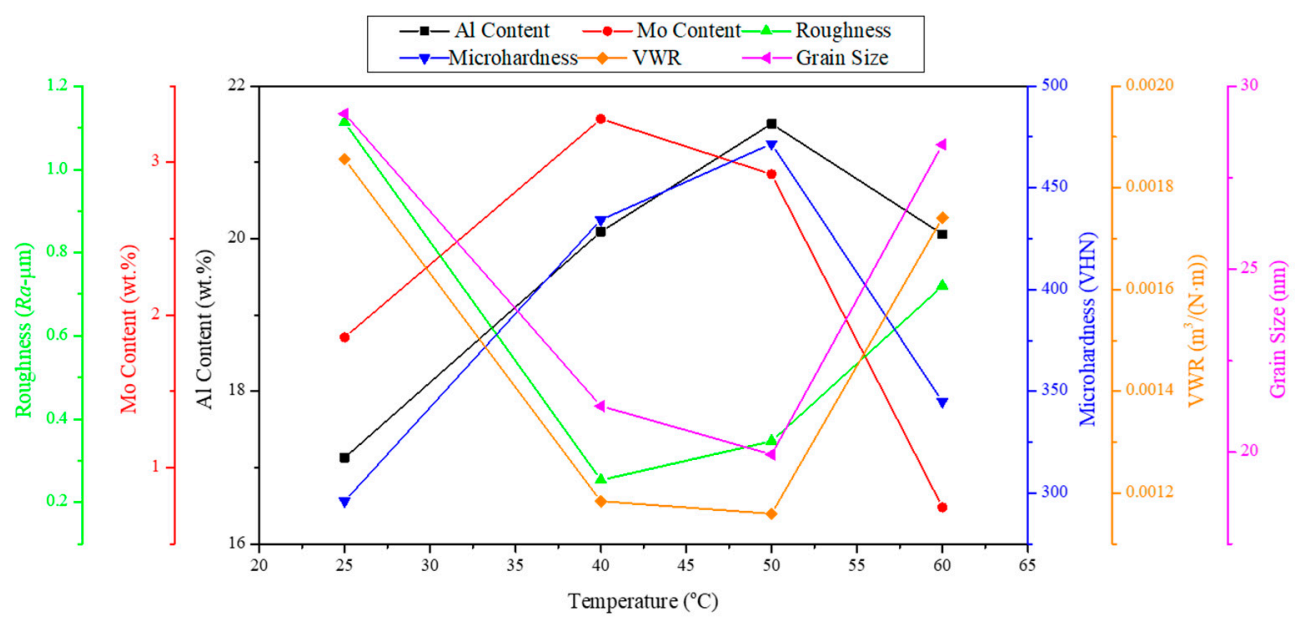

Figure 1. The effect of temperature on the grain size, chemical composition, volumetric wear rate (VWR), roughness, and microhardness properties of the coatings obtained at the current density of $30 \mathrm{~mA} / \mathrm{cm}^{2}, \mathrm{Al}$ content in the solution of $5 \mathrm{~g} / \mathrm{L}$, stirring rate of $500 \mathrm{rpm}$, and different temperatures.

Lopez-Valdivieso et al. [19] determined the zeta potential of $\alpha-\mathrm{Al}_{2} \mathrm{O}_{3}$ in $0.01 \mathrm{~mol} \mathrm{dm}^{-3}$ aqueous $\mathrm{NaNO}_{3}$ at $10,20,30$, and $40{ }^{\circ} \mathrm{C}$ as a function of $\mathrm{pH}$. They found that the zeta potential of particles, at any $\mathrm{pH}$, is shifted to more negative potentials as the temperature increases. Halter also reported that for given $\mathrm{pH}$ value, an increase in temperature decreases the zeta potential, which also indicates proton desorption from the surface [20]. Generally, the increasing temperature causes a shift of the isoelectric point (IEP) to lower values (At the isoelectric point (IEP), the net charge of the particles becomes zero, and they stop migrating). Consequently, the ability of the corporation into a deposition and the range of stability of positive particles are decreased, which are not favorable for electrophoresis. As the maximum incorporation of each particle appears at a specific temperature, particles under such conditions should have positive surface charges up to that temperature and negative surface charges beyond that temperature. These results show that increasing temperature does not favor particle adsorption.

The SEM images of the surface morphologies of the Ni-Mo/Al composite coatings are presented in Figure 2A,B. The coatings were crack-free; however, one can see when the temperature rises to $60^{\circ} \mathrm{C}$, the particles tend to agglomerate. On the other hand, it seems that the distribution of $\mathrm{Al}$ particles and the morphologies of the coatings obtained at temperatures less than $50^{\circ} \mathrm{C}$ were more uniform than for the other coating obtained at higher temperature. For all conditions which were reported in this article, a tendency to agglomerate was due to the high surface free energy of fine $\mathrm{Al}$ metallic particles.
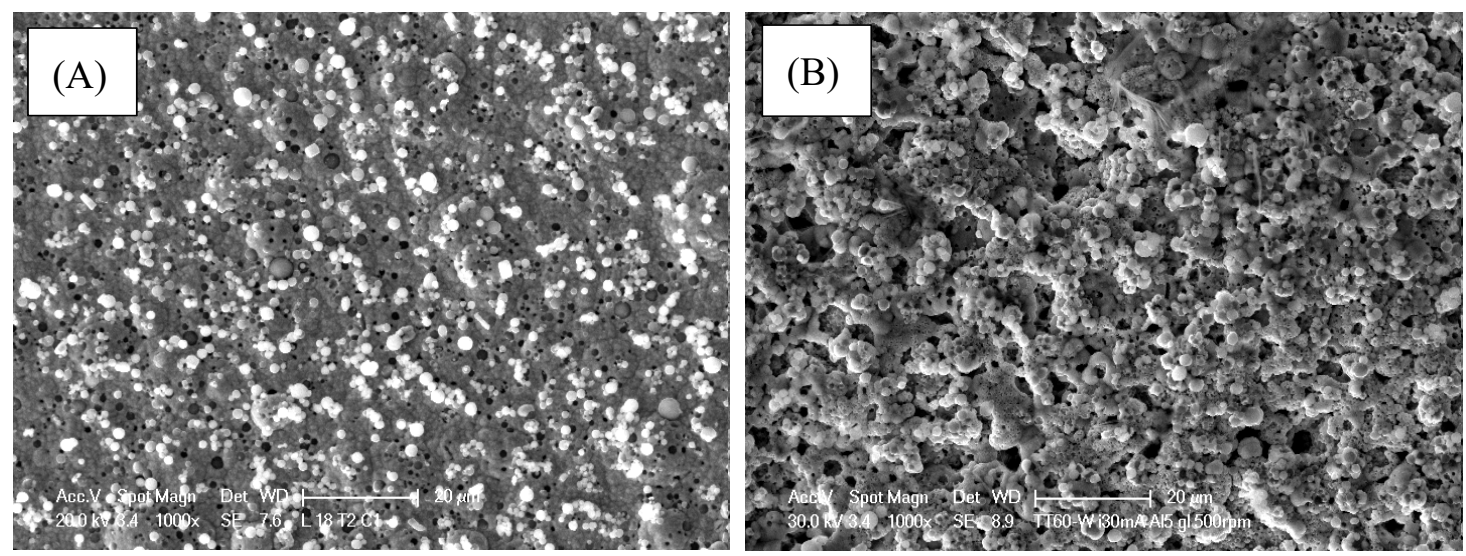

Figure 2. Surface morphologies of coatings obtained at the current density of $30 \mathrm{~mA} / \mathrm{cm}^{2}, \mathrm{Al}$ content in the solution of $5 \mathrm{~g} / \mathrm{L}$, stirring rate of $500 \mathrm{rpm}$, and different temperatures: (A) 40 and (B) $60{ }^{\circ} \mathrm{C}$. 
As can be seen in Figure 1, it is obvious that as the temperature increases, the weight loss decreases gradually. Then it remains constant at temperatures of $40-50{ }^{\circ} \mathrm{C}$ and then increases with a further increase in temperature.

Surface roughness also affects the wear resistance of the material. Figure 1 shows the roughness values of the $\mathrm{Ni}-\mathrm{Mo} / \mathrm{Al}$ composite coatings obtained at different temperatures. As seen, the roughness of the composites shows the same behavior as the wear properties with increasing temperature. It is reduced and reaches a minimum at $40-50^{\circ} \mathrm{C}$, and then increases with a further increase in temperature. Higher roughness indicates the presence of agglomerates, which is confirmed by SEM image. A higher roughness causes the particles to be removed from the coating during the wear test. The resulting surface roughness increases the friction coefficient that leads to the loss of much more weight of coatings [21,22].

The microhardness values of $\mathrm{Ni}-\mathrm{Mo} / \mathrm{Al}$ composite coatings are also shown in Figure 1. The microhardness of the Ni-Mo/Al composite coatings increases up to $471 \mathrm{HV}$ at $50{ }^{\circ} \mathrm{C}$ and then decreases to $345 \mathrm{HV}$ with a further increase in temperature. The results suggested that the weight loss was declined with the rise of the hardness and decrease of the roughness. These results show that there is a relation between roughness and hardness with wear resistance. This achievement was approved by some references [6,23-26]. Narasimman et al. [23] confirmed that the weight loss of the coatings increased considerably with an increase in the surface roughness. Eslami et al. also reported that the grain sizes and microhardnesses of coatings are decreased and increased, respectively, by adding particles to the matrices of coatings [24,27]. According to the literatures, increasing the hardness of a coating can be related to the three reasons [28,29]: (1) the presence of a particle, (2) the distribution of a particle, and (3) the grain refining. The presence of a particle increases hardness when the particle is hard and its volume fraction is higher than $20 \%$, and particle dispersion also increases hardness and strength when the size of the incorporated particle is fine $(<1 \mu \mathrm{m})$ and its volume fraction is less than $15 \%$. In this case, the $\mathrm{Al}$ particles are softer than the Ni matrix, so the load is not carried by the $\mathrm{Al}$ particles, and the particles cannot restrain the matrix deformation and hinder dislocation motion. Consequently, the first and second strengthening mechanisms cannot be accepted as the main strengthening mechanisms in this case. Susan et al. [30] reported the third strengthening mechanism of coatings by metallic particles. According to the proposed mechanism, if the particles are electrically conductive, they effectively become part of the cathode surface and can stimulate the nucleation sites, and they reduce the grain size of the coating. Based on this property, they claimed that when the $\mathrm{Al}$ particles are incorporated into a growing Ni matrix, new grains nucleate on the surface of the Al. The small grains produce a refined microstructure in comparison to a pure nickel coating deposited under similar conditions. The effect of temperature on the grain size of coatings was shown in Figure 1. An investigation of the surface morphology of a Ni/Al composite coating by Susan et al. [30] provided further evidence that the A1 particles act as sites for enhanced growth of the nickel deposit. Thus, it has been concluded that additions of A1 particles to the Ni matrix can produce hardening by a structural refinement mechanism. The existence of smaller grains hinders the dislocation motion, leading to an expansion in microhardness. Increasing the wear resistance by increasing the hardness, due to the reduction of grain size, has been often expressed by Archard's law [31], which gives the relationship between wear volume loss $(V)$, applied load $(L)$, sliding distance $(S)$, and hardness of the wearing surface $(H)$.

$$
\Delta V=k \cdot L \cdot S / H(k: \text { wear coefficient })
$$

This equation represents that there is an inverse correlation between the wear behavior and surface hardness, and accordingly, the coating wear reduces as its surface hardness rises. This relation is in agreement with the results of the current study.

As seen in Figure 1, although the amount of $\mathrm{Al}$ content in the coating at $60{ }^{\circ} \mathrm{C}$ was less than that at $50{ }^{\circ} \mathrm{C}$, the microhardness of composite coating was decreased. Generally, the weight loss of a coating during a wear test was extensively affected by its porosity [32]. It seems that according to Figure $2 \mathrm{~B}$, agglomeration of $\mathrm{Al}$ particles and porosity at this temperature are the main reasons for 
decreasing microhardness. In other words, aluminum particles have a complex effect on hardness. Since $\mathrm{Al}$ is a soft metal, for coatings with higher amounts of Al particles, each indentation will touch several A1 particles along with the Ni matrix. Hence the hardness of the A1 particles begins to affect the overall hardness.

Figure 3 shows the effect of temperature on the X-ray diffraction pattern of the coating.

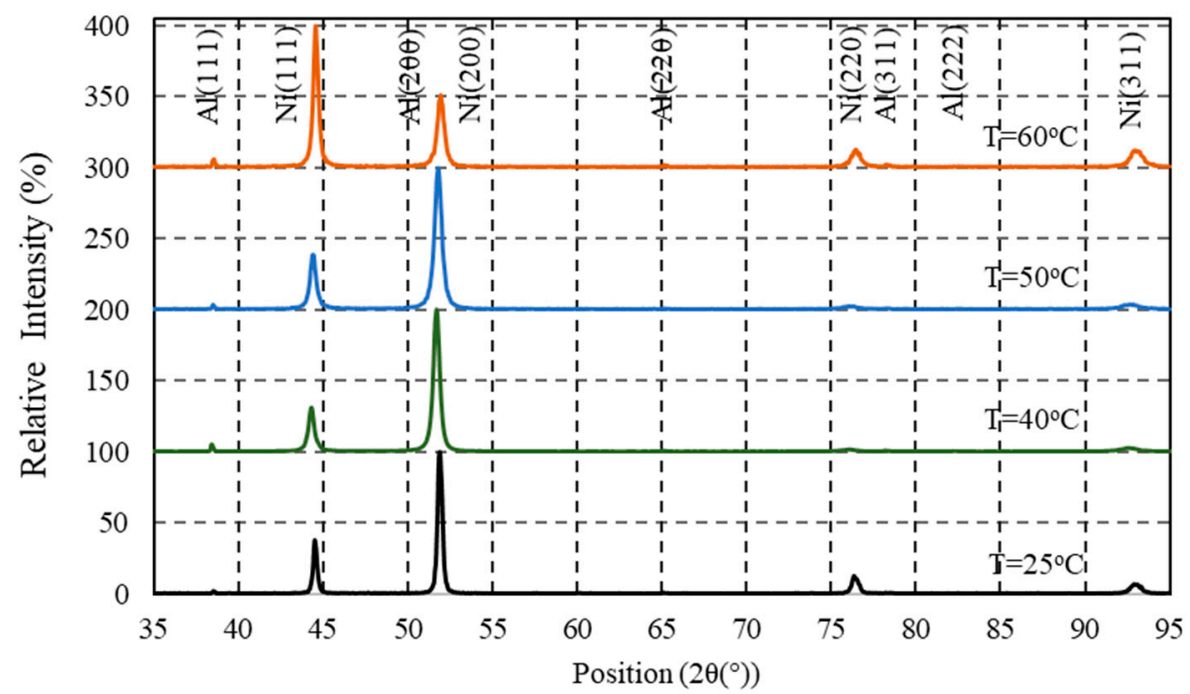

Figure 3. The XRD patterns of $\mathrm{Ni}-\mathrm{Mo} / \mathrm{Al}$ composite coatings obtained at different temperatures.

It was demonstrated that $\mathrm{Ni}-\mathrm{Mo} / \mathrm{Al}$ composite coatings around $40-50{ }^{\circ} \mathrm{C}$ show a maximum wear resistance and microhardness with a further increase in temperature. As is seen in Figure 3, two planes $\mathrm{Ni}(111)$ and $\mathrm{Ni}(200)$ have the main intensity and confirm that these two planes compose the most surface area of coatings. As can be seen, the intensities of $\mathrm{Ni}$ (111) and $\mathrm{Ni}(200)$ peaks increased and decreased with increasing temperature, respectively. The slip plane of a face-centered cubic (fcc) lattice is the (111) plane, a crystallographic plane whose atomic density is highest than any other plane [4]. Consequently, despite that (200) planes have lower planar density and lower wear resistance than that of the (111) planes in the fcc structure, the weight loss of $\mathrm{Ni}-\mathrm{Mo} / \mathrm{Al}$ composite coatings at $40-50{ }^{\circ} \mathrm{C}$ with the predominantly (200) planes is low. Therefore, it is decided that the chemical composition of the $\mathrm{Ni}-\mathrm{Mo}$ matrix can have both a positive influence and a negative impact on the weight loss of Ni-Mo/Al composite coatings. As a consequence, besides the chemical composition, phase structure is also another significant factor altering the wear property of composite coatings. On the other hand, besides the negative effect of the presence of the low density (200) planes with high friction, another reason for decreasing the wear rate and increasing microhardness of the Ni-Mo/Al composite coatings with rising temperature up to $40-50{ }^{\circ} \mathrm{C}$, can be attributed to their grain sizes, which was explained by reference [30]. As it was shown in Figure 1, by increasing the temperatures beyond the $50{ }^{\circ} \mathrm{C}$, the deposited $\mathrm{Al}$ content in the coating decreases, which can be followed by increasing grain size. Because by increasing temperature beyond the $50{ }^{\circ} \mathrm{C}$ and decreasing $\mathrm{Al}$ content, the wear rate is intensively increased. It is known that the Hall-Petch equation can empirically describe the relationship between flow stress and grain size. This equation relates the grain size, $d$, with the hardness, $H$, of a metal:

$$
H=H_{\mathrm{o}}+K_{\mathrm{H}} d^{-1 / 2}
$$

The terms of $H_{\mathrm{o}}$ and $\mathrm{K}_{\mathrm{H}}$ are experimental constants and are different for each metal. As shown in Figure 3, when increasing the temperature up to $50^{\circ} \mathrm{C}$, both the peak intensity of the (100) planes and their full width at half maximum (FWHM) increase. This simultaneous increase in peak intensity and FWHM respectively indicate that the number of the (100) planes increased on the surface of the coating, and the size of the grains containing these planes decreased. In contrast to decreasing in wear resistance 
by increasing the number of the (100) crystalline planes, decreasing the size of grains containing the (100) planes increases the wear resistance in which the grain size effect is more effectiveness than the effect of increasing the number of (100) planes on the wear resistance.

The values of thickness obtained at different temperatures were also assigned in Figure 4. As seen in this figure, the thickness of coatings is raised to a maximum value at $40^{\circ} \mathrm{C}$, and then decreased with further increase in temperature. Decreasing thickness can be related to the current efficiency. Raising the temperature usually leads to the decreases in polarization, improves the metallic ions concentration in the interface between electrolyte and cathode electrode, and may influence the current efficiency in depositing metals, especially those deposited from complex ions [18,33]. It seems that by increasing the temperature up to $40^{\circ} \mathrm{C}$ in this case, the concentration of metallic ions in the diffusion layer is raised and then decreases by further increases in the temperature. As seen in Figure 4, the total of the metallic part of the coatings reached a maximum at $40{ }^{\circ} \mathrm{C}$ and then started to reduce by further increases in the temperature, which confirmed that hydrogen evolution reaction is the dominant cathode reaction and consumes the most part of deposition current. Under this condition, metallic ions could not deposit much more. For this purpose, at the first step, the weight of the Al powder was subtracted from the total weight of coating and the remaining weight was the weight of $\mathrm{Ni}$ and Mo elements, which consumed electrons and electrical current. As can be seen, the highest weight of metallic elements (current efficiency) is obtained at $40^{\circ} \mathrm{C}$, and then decreased sharply with increasing temperature.

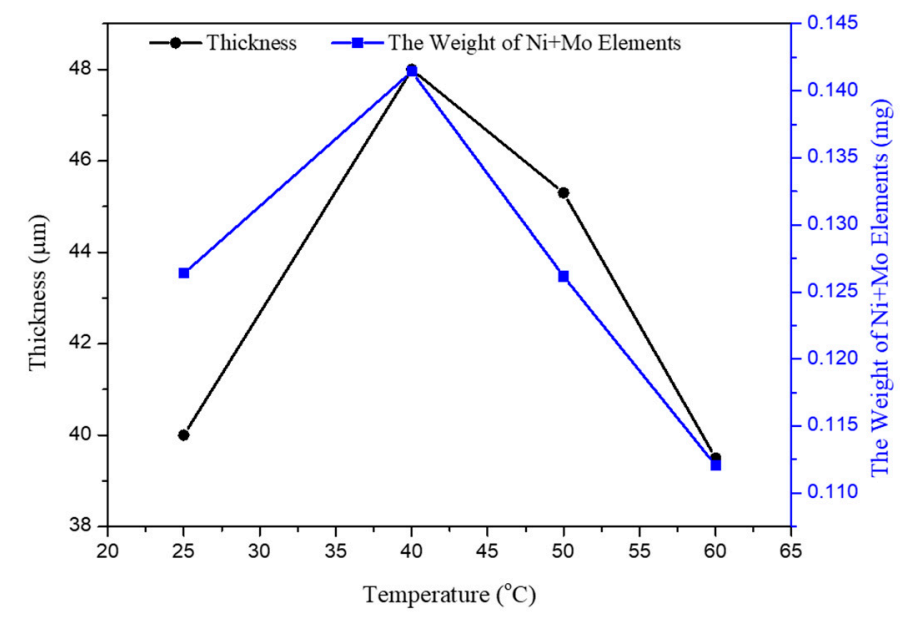

Figure 4. The effect of temperature on the weight of deposited $\mathrm{Ni}+\mathrm{Mo}$ elements in the coatings and thicknesses of coatings obtained at the conditions mentioned in the caption of Figure 1.

\subsection{Current Density Effect}

The velocity $\left(v_{\mathrm{E}}\right)$ of a charged particle moving in an electric field $(E)$ is expressed by the Smoluchowski equation [34]:

$$
v_{\mathrm{E}}=u_{\mathrm{E}} E=(\varepsilon \zeta) /\left(\eta_{\mathrm{E}}\right)
$$

where $E$ is the applied electrical field strength, $u_{\mathrm{E}}$ is the electrophoretic mobility of the particle, $\zeta$ is the zeta potential, $\varepsilon$ is the dielectric constant of the electrolyte, and $\eta$ is the viscosity of the suspension.

According to the equation, as the electric field intensifies, the velocity of the charged particle also increases. This means that as the electric field increases, the amount of precipitated particles in the coating also increases. Many articles have reported that the particle content of deposit is drastically changed when the current density is modified. Vaezi et al. showed that $\mathrm{SiC}$ content increases up to a maximum value then decreases with increasing current density [7]. Bakhit et al. [35], Shi et al. [6], Tripathi et al. [36], and Wang et al. [37] have reported a similar trend. It was seen that Al particles also show similar behavior. Al content in the deposit increases up to a maximum at $50 \mathrm{~mA} / \mathrm{cm}^{2}$ and then decreases with increasing current density (Figure 5). Decreasing Al deposited at higher current 
densities $\left(>50 \mathrm{~mA} / \mathrm{cm}^{2}\right)$ can be attributed to the high velocity of charged particles. Under this condition, fewer particles are embedded in the coating.

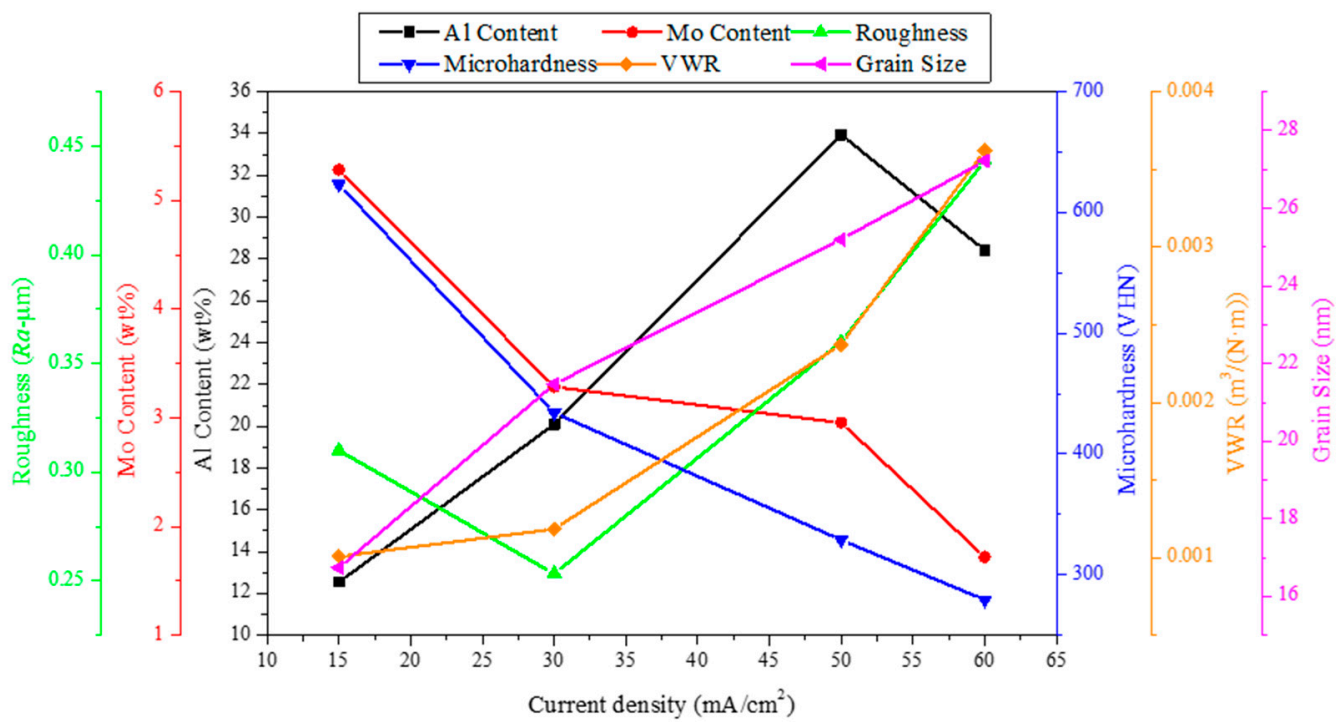

Figure 5. The effect of current density on the grain size, chemical composition, volumetric wear rate (VWR), microharness, and roughness properties of coatings obtained at the temperature of $40^{\circ} \mathrm{C}, \mathrm{Al}$ content in the bath of $5 \mathrm{~g} / \mathrm{L}$, stirring rate of $500 \mathrm{rpm}$, and different current densities.

SEM images of the surface morphologies of the Ni-Mo/Al composite coatings are presented in Figure $6 \mathrm{~A}, \mathrm{~B}$. The coatings were crack-free. The effect of current densities on the weight loss of Ni-Mo/Al composite coatings during the wear test are shown in Figure 5. Generally, from the data shown in this figure, it is clear that the weight loss gradually increases with an increase in current density up to $30 \mathrm{~mA} / \mathrm{cm}^{2}$ and then sharply increases with a further increase in current density.
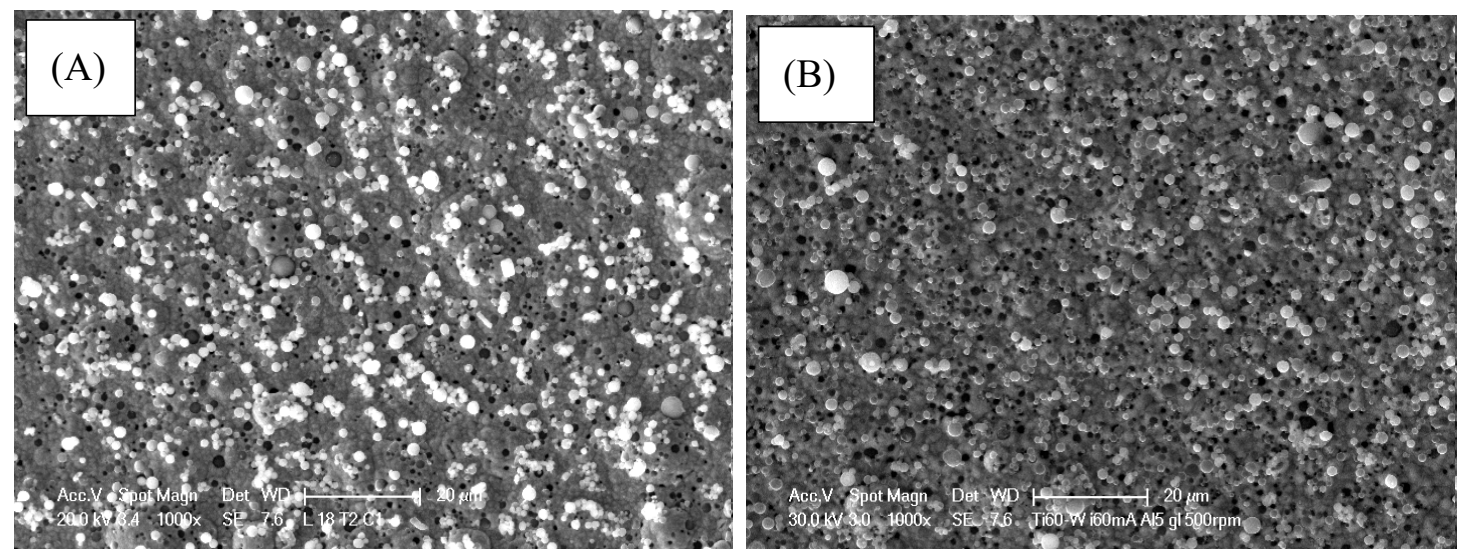

Figure 6. Surface morphology of coatings obtained at the temperature of $40{ }^{\circ} \mathrm{C}, \mathrm{Al}$ content in the bath of $5 \mathrm{~g} / \mathrm{L}$, stirring rate of $500 \mathrm{rpm}$, and different current densities: (A) 30, and (B) $60 \mathrm{~mA} / \mathrm{cm}^{2}$.

As can be seen in Figure 5, the roughness of the composites is increased with a further increase in current density. Like the effect of temperature, the resulting surface roughness increases the friction coefficient; that leads to loss of much more weight of the coatings [21].

The microhardness of $\mathrm{Ni}-\mathrm{Mo} / \mathrm{Al}$ composite coatings under the same condition was shown in Figure 5. The microhardness of the Ni-Mo/Al composite coating is decreased from 614 to $280 \mathrm{VHN}$, with a further increase in current density from 15 to $60 \mathrm{~mA} / \mathrm{cm}^{2}$. The result suggests that the wear 
resistance is decreased with decreasing microhardness and increasing roughness. These results show that there is a relation between roughness and hardness with wear resistance.

The crystallite size refinement and the texture evolution played important roles in the improvement of the wear property. Thus, it will be discussed in the following. As shown in Figure 7, XRD line profiles of Ni-Mo/Al composite coatings change with increasing current density. By increasing the current density, the strongest diffraction reflection is changed from (111) (for a pure nickel) to (200) diffraction peak, implying the texture evolution of the electrodeposited Ni-Mo matrix coatings. A two-component texture of the $\{100\}$ and $\{111\}$ is frequently observed in nanocrystalline $\mathrm{Ni}$ and its alloys [38]. However, as it is seen, with the increasing of current density, the intensity percentage of (200) increases and the intensity percentage of (111) decreases. As the current density increased, the (111) orientation disappeared. The same results were reported by other references [39]. The Al peaks were also observed for coatings deposited at different current densities. As it was also mentioned in the section of temperature effect, since the total number of atoms present on the surface of (200) is less than the (111) plane, the friction force on this kind of surface will be high compared to the (111) planes with high packing factor. Therefore, it is reasonable to decide that the wear rate is increased due to increasing the predominant (200) planes and surface roughness of $\mathrm{Ni}-\mathrm{Mo} / \mathrm{Al}$ composite coating with increasing current density. However, the presence of the predominant (200) plane and high roughness values cannot be accepted as the main reasons for this low microhardness. Despite the fact that the (200) plane was also the predominant crystallographic orientation for increasing temperature in the section of temperature effect, the composite coating had the highest wear resistance and microhardness. Thus, it was concluded that decreasing grain size with increasing temperature was the predominant strengthening mechanism. Similarly, as seen in Figure 7, as the electrodeposition current density increases, the FWHM decreases, which indicates an increase in the grain size of the (200) crystalline plates. According to this interpretation, the grain coarsening by increasing current density can be considered as the main reason for decreasing wear resistance and microhardness and increasing roughness. Consequently, it seems that the grain size of coatings is simultaneously affected by current density and $\mathrm{Al}$ particles in which each of them has an opposite effect on the grain size. It means that grain size is increased and decreased by increasing current density and Al particles content by two different rates, respectively. The rate of grain coarsening due to increasing current density is more than that of grain refining. There is evidence which shows that the rate of grain coarsening is the predominant mechanism, as follows: the first piece of evidence is that the peak width increases by increasing the current density, as is seen in Figure 7. Careful examination shows that the XRD peaks of $\mathrm{Ni}-\mathrm{Mo} / \mathrm{Al}$ composite coatings at low current density, e.g., $15 \mathrm{~mA} / \mathrm{cm}^{2}$, is wider than that of the coating obtained at high current density; e.g., $60 \mathrm{~mA} / \mathrm{cm}^{2}$. The second reason can be attributed to the decreasing microhardness with a further increase in the current density. The relationship between wear resistance and microhardness, in this case, is also satisfied the Archard's law [31], which was discussed in the section of the temperature effect. Consequently, it can be decided that decreasing the microhardness of Ni-Mo/Al composite coating is due to the grain coarsening, which happens during increasing current density. From the above results, it could be concluded that the deterioration of wear resistance of $\mathrm{Ni}-\mathrm{Mo} / \mathrm{Al}$ coatings was linked to the combined effect of incorporation of grain coarsening and texture evolution from (111) plane to predominant (200) plane. 


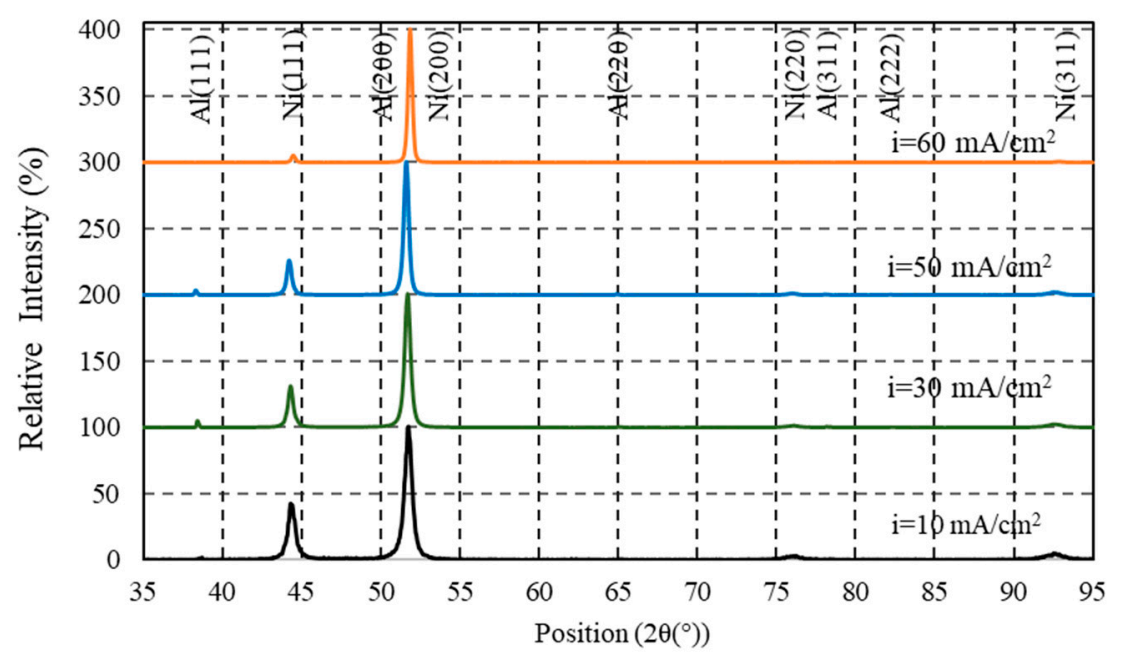

Figure 7. The XRD pattern of Ni-Mo/Al composite coatings obtained at different current densities.

The values of thickness obtained at different current densities were assigned in Figure 8. As is shown, the thickness of coatings decreases with increasing current density. Decreasing thickness with increasing current density can be linked to the current efficiency which decreased by increasing current density. The current efficiency of the bath at different current densities is also shown in Figure 8. For this purpose, at the first step, the temperature effect section, the weight of the Al powder was subtracted from the total weight of coating and the remaining weight was the weight of $\mathrm{Ni}$ and Mo elements, which consume electrons and electrical current. As can be seen, the most efficiency is obtained at low current density, $15 \mathrm{~mA} / \mathrm{cm}^{2}$. As is shown, the efficiency is deteriorated with a further increase in current density. It means that the current parameter deteriorates the current efficiency and decreases thickness. At a higher current density, the reaction of hydrogen evolution could become increasingly dominant. This could lead to a smaller current used for the deposition of $\mathrm{Ni}$ and Mo as metallic elements to form the matrix. As it is shown in Figure 8, the weight of coating as a criterion for efficiency is reduced by increasing current density, which is shown that a part of current was consumed by hydrogen evolution.

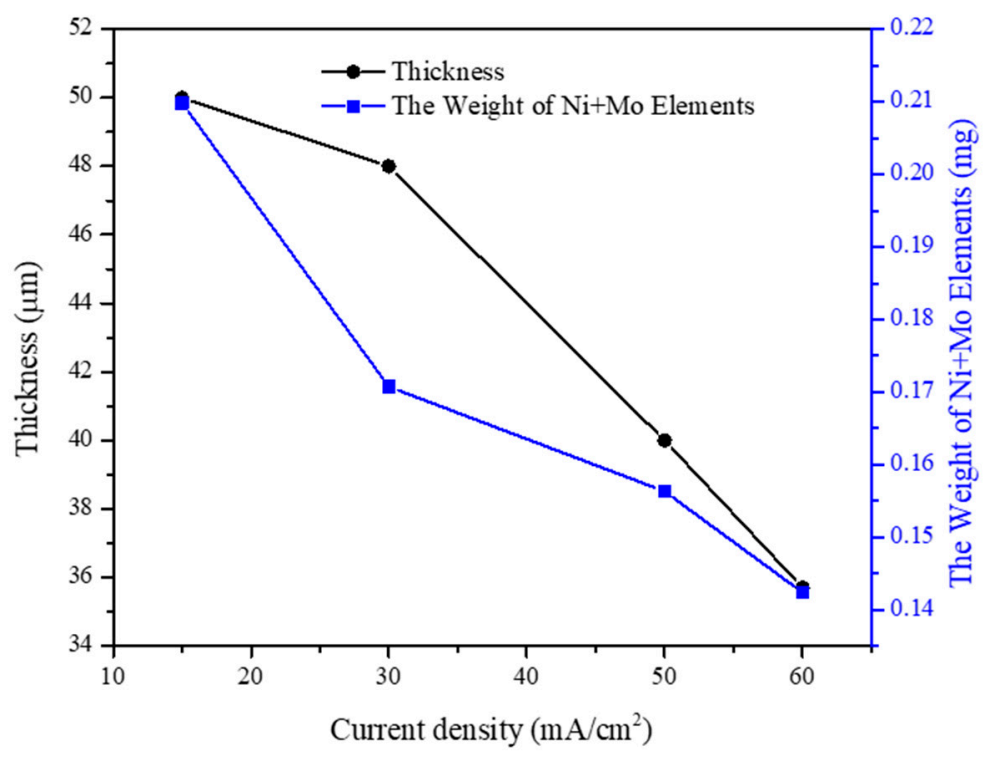

Figure 8. The effect of current density on the thickness of coatings and the weight of deposited $\mathrm{Ni}+$ Mo elements in the coatings obtained at the mentioned conditions in the caption of Figure 5. 


\subsection{Stirring Rate Effect}

Many investigations have found that incorporating particles in an electrodeposited coating increases up to a maximum then decreases by increasing stirring rate $[10,15,40-44]$. This means that excessive agitation may lead to a lower particle loading in the metal deposits. On the other hand, there is a critical stirring rate, after which the stirring rate can have a negative effect on the incorporation of particles in the coatings. This result can be related to the effect of hydrodynamic forces proposed by Buelens et al. [45]. They proposed that, depending on the Reynolds number, laminar, transition, or turbulent flow regimes are possible. According to their reported results, at the beginning before a critical value, the flow regime is either laminar or transitional, and the amount of deposited particles will be constant or increase at a higher stirring rate, respectively. Beyond a critical stirring rate, increasing the stirring rate in the suspension may also sweep away loosely adsorbed particles from the cathode surface and decrease the concentration of deposited particles in the composite coating [44]. It is shown in Figure 9 that the stirring rate strongly affects the weight percentage of the co-deposited $\mathrm{Al}$ particles, since Al should be transported to the cathode surface for the co-deposition with the Ni-Mo matrix. The behavior of $\mathrm{Al}$ particle in this work is the same as in the results reported by the literature. As the stirring rate increases further, deposited particles decrease drastically.

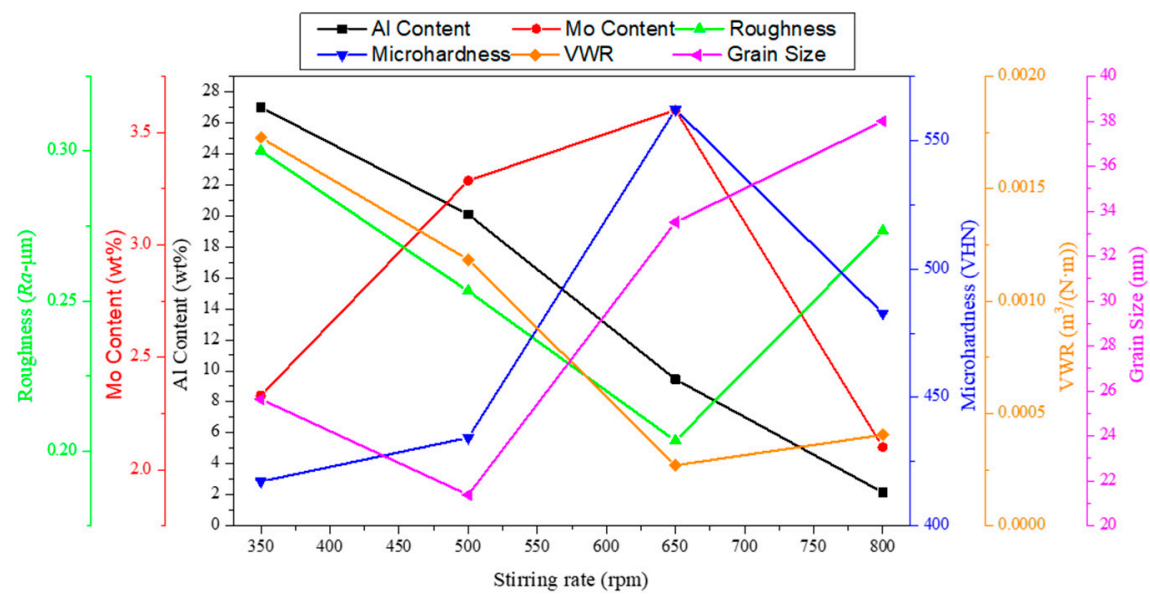

Figure 9. The effect of stirring rate on the grain size, chemical composition, volumetric wear rate (VWR), roughness, and microhardness properties of coatings obtained at current density of $30 \mathrm{~mA} / \mathrm{cm}^{2}$, temperature of $40^{\circ} \mathrm{C}, \mathrm{Al}$ content in the solution of $5 \mathrm{~g} / \mathrm{L}$, and different stirring rates.

SEM micrographs, presented in Figure 10, illustrate different morphologies of the Ni-Mo/Al composite coating. It is evident that the co-deposited $\mathrm{Al}$ particles are uniformly distributed in the Ni-Mo matrix by electrodeposition. It is important to disperse the $\mathrm{Al}$ particles very well in the electrolyte. As long as the $\mathrm{Al}$ particles in the coatings are uniformly distributed, $\mathrm{Ni}-\mathrm{Mo} / \mathrm{Al}$ composite coatings could possess excellent mechanical and corrosion resistance properties. Al particles cathodically adsorb on the surface, and $\mathrm{Ni}$ and Mo metal elements are simultaneously reduced and make matrix, and enfold Al particles. Some Al particles were dipped in the matrix and pulled out of the surface and left dark holes. A part of $\mathrm{Al}$ particles that adsorbed on the surface at the last time as electrodeposition remain on the surface, and these sites are seen bright and white. 


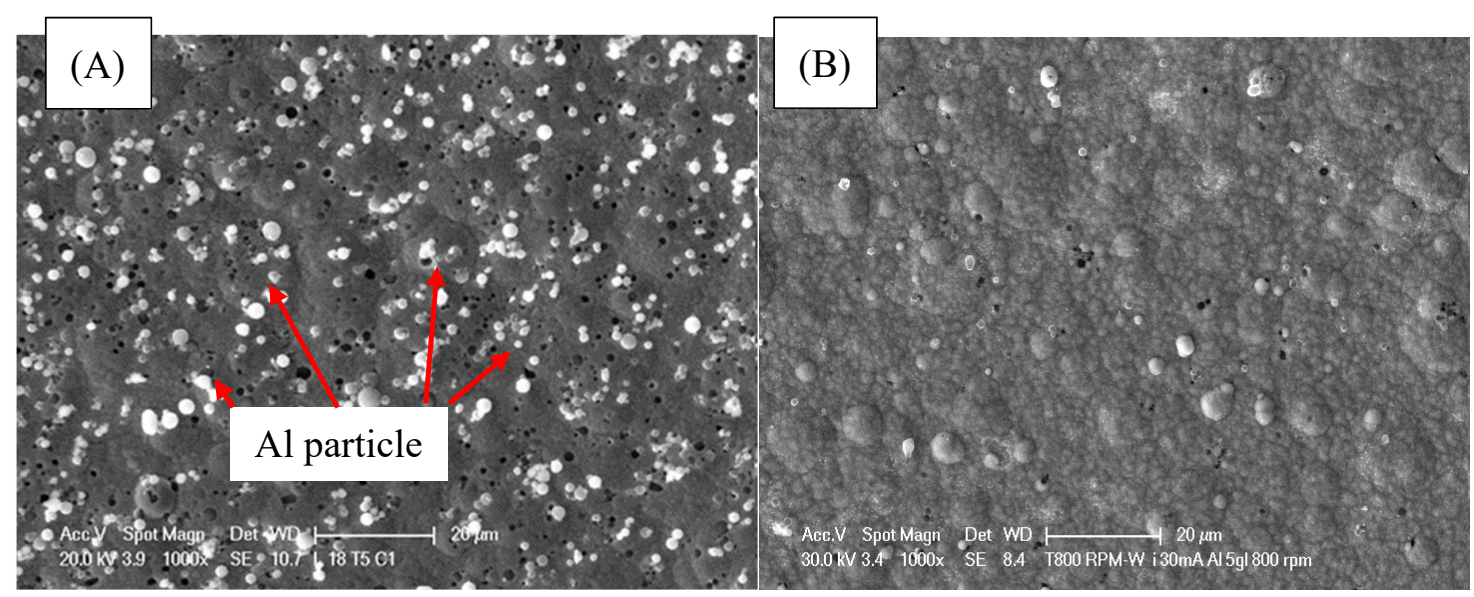

Figure 10. Surface morphology of coatings obtained at current density of $30 \mathrm{~mA} / \mathrm{cm}^{2}$, temperature of $40{ }^{\circ} \mathrm{C}, \mathrm{Al}$ content in the solution of $5 \mathrm{~g} / \mathrm{L}$, and different stirring rates: (A) 650, and (B) $800 \mathrm{rpm}$.

From the data shown in Figure 9, it is clear that the wear loss gradually decreases with an increase in stirring rate, attains a minimum at $650 \mathrm{rpm}$, and then increases with a further increase in stirring rate.

Figure 9 shows the roughness values of the $\mathrm{Ni}-\mathrm{Mo} / \mathrm{Al}$ composite coatings obtained at different stirring rates. As it is seen, the roughness of the composites shows the same behavior as wear property with an increasing stirring rate. Higher roughness indicates the presence of agglomerates, which is confirmed by SEM image. A higher roughness value leads to easily pull off of the particles in wear testing. The resulting surface roughness increases the friction coefficient; that leads to loss of much more weight of coatings [21]. It is clear that the roughness was decreased by increasing the stirring rate and reached a minimum at $650 \mathrm{rpm}$, then increased by increasing the stirring rate.

The microhardnesses of Ni-Mo/Al composite coatings obtained at different stirring rates are shown in Figure 9. The results suggest that the wear resistance increased with increasing microhardness and decreasing roughness. These results show that there is a relation between roughness and hardness with wear resistance. It is seen in Figure 9, the microhardness of coatings is increased by increasing the stirring rate, reaches a maximum at $650 \mathrm{rpm}$, and then decreases by further increases in the stirring rate.

Similarly to the last two sections, the crystallite size refinement played important roles in the improvement of the wear behavior. Thus, it will be discussed in the following paragraph.

As shown in Figure 11, XRD line profiles of Ni-Mo/Al composite coatings change with increasing stirring rate. By increasing the stirring rate, the most powerful diffraction reflection is changed from (200) to (111) diffraction peak, implying the texture evolution of the electrodeposited Ni-Mo matrix coatings. As is seen, with increasing stirring rate, the intensity percentage (200) decreased, and the intensity percentage (111) increased. As the stirring rate increased, the (111) orientation became an absolute peak, which was a peak with very weak intensity at low stirring rates; e.g., $350 \mathrm{rpm}$. This behavior is very favorite for obtaining a coat with high microhardness and wear. Because the total number of atoms present on the surface of (111) is more than the (200) plane, the friction force on these kinds of surfaces will be low compare to the (200) planes with high packing factor. Therefore, it is reasonable to decide that the wear rate should be decreased due to increasing the predominant (111) planes and decreasing surface roughness of $\mathrm{Ni}-\mathrm{Mo} / \mathrm{Al}$ composite coating with increasing the stirring rate. 


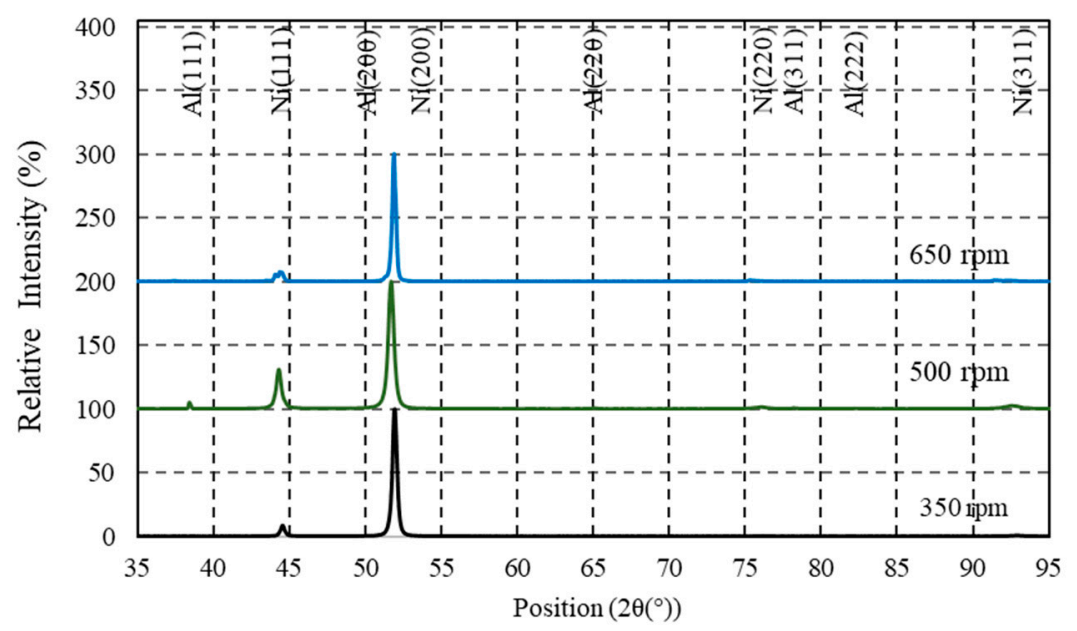

Figure 11. XRD patterns of coatings obtained with the conditions mentioned in the caption of Figure 9.

However, the presence of the predominant (111) plane and low roughness values cannot be accepted as the main reasons for this high microhardness. As can be seen from XRD patterns, with increasing stirring rate, FWHM first increased and then decreased, indicating a decrease and increase in grain size, respectively. Accordingly, it must be a factor that increases grain size and decreases the wear rate. It was demonstrated and reported frequently that the grain size of coatings is increased by decreasing the amount of inclusion particles in the composite coatings and vice versa $[14,46,47]$. A was seen in Figure 11, Al content was intensively decreased by increasing the stirring rate. Reducing the amount of aluminum particles in the coating can increase grain size while reducing wear rates. With the decrease in the amount of aluminum particles, the intensity of nucleation sites decreases. So, the grain coarsening can be linked to the decreasing of $\mathrm{Al}$ particles in the coating. On the other hand, since aluminum is a soft metal, the hardness increases with decreasing the number of $\mathrm{Al}$ particles in the coating. As a consequence, decreasing $\mathrm{Al}$ content by increasing the stirring rate can be considered as the main reason for increasing wear resistance, microhardness, and grain size. Consequently, it seems that the properties of coatings are mainly affected by the presence of $\mathrm{Al}$ particle.

On the other hand, a part of the increasing in grain size due to the decreasing of the amount of $\mathrm{Al}$ particles is compensated by the stirring operation. In other words, mixing prevents a drastic reduction in grain size due to the decrease in the amount of aluminum particles. The proportionate rates of the formation of crystal nuclei and the growth of the existing crystals powerfully affected the crystal structure obtained from an electrodeposition process. The conditions that favor crystal nuclei formation lead to the finer-grained deposits, while larger crystals are formed in those cases that support the growth of the existing crystals [4]. Thus, contrary to the effect of the Al particles on the grain size, it seems that agitation promotes the formation of crystal nuclei, because the agitation can directly affect the composition of the alloy by reducing the thickness of the cathode diffusion layer. Figure 12 confirms this idea. As is seen, the weight of deposited metallic elements or current efficiency was increased by increasing the stirring rate, which reveals that the concentration of metallic ions in the diffusion layer was increased.

As can be observed, the highest efficiency is obtained at a high stirring rate, $800 \mathrm{rpm}$. That means that the stirring rate parameter has a beneficial effect on the current efficiency while it decreases contradictory thickness. The values of thickness obtained at different stirring rates were assigned in Figure 12. As is seen, the thickness of coatings reached a maximum value at $500 \mathrm{rpm}$, and then decreased with a further increase in the stirring rate. Decreasing the thickness is related to decreasing the amount of $\mathrm{Al}$ particles in the coatings. The participation of particles in the coatings has a direct effect on the thickness value. 


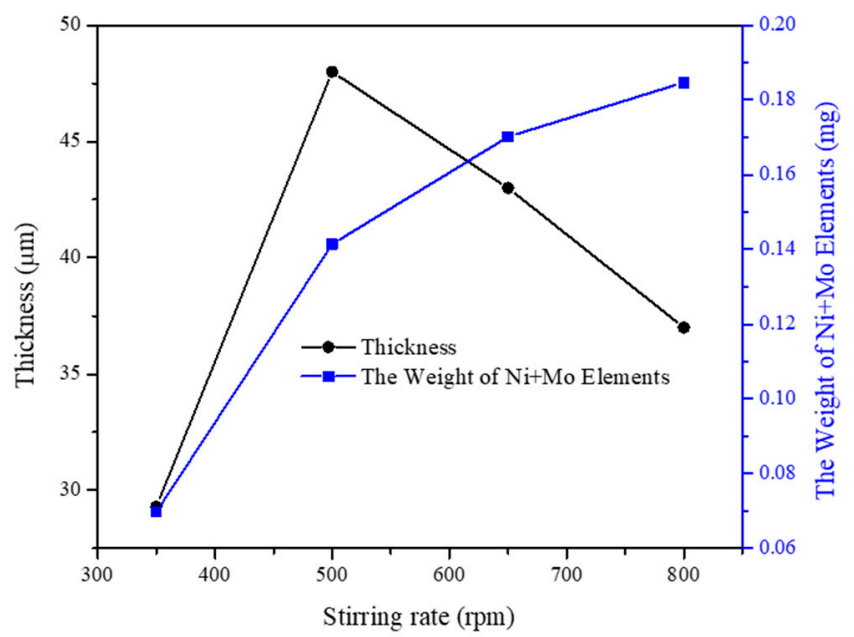

Figure 12. The effect of stirring rate on the weight of deposited $\mathrm{Ni}+$ Mo elements in the coatings obtained at the mentioned conditions in the caption of Figure 9.

\section{Conclusions}

$\mathrm{Ni}-\mathrm{Mo} / \mathrm{Al}$ composite coatings were made by using a citrate bath containing Al particles. The effects of some operating parameters on the morphology, microhardness, roughness, current efficiency, Al particle content in the coatings, and wear properties of the $\mathrm{Ni}-\mathrm{Mo} / \mathrm{Al}$ composite coating were investigated. It was seen that mentioned properties, especially the $\mathrm{Al}$ particle content in the coatings, showed parabolic behavior by changing investigated operating parameter, which means that there is a critical value for the mentioned parameters, at which the properties of coatings become maximal.

It was found that the A1 particles act as sites for enhanced growth of the nickel deposit. The addition of A1 particles to the Ni matrix can produce hardening by a structural refinement mechanism. During increasing current density, the deterioration of wear resistance of $\mathrm{Ni}-\mathrm{Mo} / \mathrm{Al}$ coatings was linked to the combined effect of incorporation of grain coarsening and texture evolution from (111) plane to predominant (200) plane.

Among all parameters, the stirring rate powerfully influences the weight percentage of the co-deposited Al. Agitation also reduces the thickness of the cathode diffusion layer and promotes the formation of crystal nuclei.

Author Contributions: Conceptualization, R.M.; methodology, R.M.; investigation, R.M.; resources, M.E.B. and F.D.; data curation, R.M., M.E.B. and F.D.; writing — original draft preparation, R.M.; writing-review and editing, R.M., M.E.B. and F.D.; visualization, R.M., M.E.B. and F.D.; supervision, M.E.B. and F.D.; funding acquisition, F.D. All authors have read and agreed to the published version of the manuscript.

Funding: This research received no external funding.

Acknowledgments: Authors are grateful for the partial support from the Trento University (Italy).

Conflicts of Interest: The authors declare no conflict of interest.

\section{References}

1. Musiani, M. Electrodeposition of composites: An expanding subject in electrochemical materials science. Electrochim. Acta 2000, 45, 3397-3402. [CrossRef]

2. Clark, D.; Wood, D.; Erb, U. Industrial applications of electrodeposited nanocrystals. Nanostrut. Mater. 1997, 9, 755-758. [CrossRef]

3. Robertson, A.; Erb, U.; Palumbo, G. Practical applications for electrodeposited nanocrystalline materials. Nanostruct. Mater. 1999, 12, 1035-1040. [CrossRef]

4. Dini, J.W.; Dini, J. Electrodeposition: The Materials Science of Coatings and Substrates; Noyes Publications: Park Ridge, NJ, USA, 1993. 
5. Ramesh Bapu, G.; Jayakrishnan, S. Development and characterization of electro deposited Nickel-Titanium Carbo Nitride (TiCN) metal matrix nanocomposite deposits. Surf. Coat. Technol. 2012, 206, 2330-2336. [CrossRef]

6. Shi, L.; Sun, C.; Gao, P.; Zhou, F.; Liu, W. Mechanical properties and wear and corrosion resistance of electrodeposited Ni-Co/SiC nanocomposite coating. Appl. Surf. Sci. 2006, 252, 3591-3599. [CrossRef]

7. Vaezi, M.; Sadrnezhaad, S.; Nikzad, L. Electrodeposition of Ni-SiC nano-composite coatings and evaluation of wear and corrosion resistance and electroplating characteristics. Colloids Surf. A Physicochem. Eng. Asp. 2008, 315, 176-182. [CrossRef]

8. Guo, Z.; Zhu, X.; Zhai, D.; Yang, X. Electrodeposition of Ni-W amorphous alloy and Ni-W-SiC composite deposits. J. Mater. Sci. Technol. 2000, 16, 323-326.

9. Narasimman, P.; Pushpavanam, M.; Periasamy, V.M. Synthesis, characterization and comparison of sediment electro-codeposited nickel-micro and nano SiC composites. Appl. Surf. Sci. 2011, 258, 590-598. [CrossRef]

10. Xue, Y.-J.; Zhu, D.; Zhao, F. Electrodeposition and mechanical properties of $\mathrm{Ni}-\mathrm{La}_{2} \mathrm{O}_{3}$ nanocomposites. J. Mater. Sci. 2004, 39, 4063-4066. [CrossRef]

11. Baghery, P.; Farzam, M.; Mousavi, A.; Hosseini, M. Ni-TiO 2 nanocomposite coating with high resistance to corrosion and wear. Surf. Coat. Technol. 2010, 204, 3804-3810. [CrossRef]

12. Napłoszek-Bilnik, I.; Budniok, A.; Łosiewicz, B.; Pająk, L.; Łagiewka, E. Electrodeposition of composite Ni-based coatings with the addition of Ti or/and Al particles. Thin Solid Film. 2005, 474, 146-153. [CrossRef]

13. Yao, Y.; Yao, S.; Zhang, L.; Wang, H. Electrodeposition and mechanical and corrosion resistance properties of $\mathrm{Ni}-\mathrm{W} / \mathrm{SiC}$ nanocomposite coatings. Mater. Lett. 2007, 61, 67-70. [CrossRef]

14. Daemi, N.; Mahboubi, F.; Alimadadi, H. Effect of plasma nitriding on electrodeposited Ni-Al composite coating. Mater. Des. 2011, 32, 971-975. [CrossRef]

15. Wang, H.; Yao, S.; Matsumura, S. Electrochemical preparation and characterization of Ni/SiC gradient deposit. J. Mater. Process. Technol. 2004, 145, 299-302. [CrossRef]

16. Aal, A.A.; Bahgat, M.; Radwan, M. Nanostructured Ni-AlN composite coatings. Surf. Coat. Technol. 2006, 201, 2910-2918. [CrossRef]

17. Corni, I.; Chater, R.; Boccaccini, A.; Ryan, M. Electro co-deposition of $\mathrm{Ni}-\mathrm{Al}_{2} \mathrm{O}_{3}$ composite coatings. J. Mater. Sci. 2012, 47, 5361-5373. [CrossRef]

18. Marinho, F.A.; Santana, F.S.; Vasconcelos, A.L.; Santana, R.A.; Prasad, S. Optimization of operational parameters and bath control for electrodeposion of Ni-Mo-B amorphous alloys. J. Braz. Chem. Soc. 2002, 13, 522-528. [CrossRef]

19. López Valdivieso, A.; Reyes Bahena, J.L.; Song, S.; Herrera Urbina, R. Temperature effect on the zeta potential and fluoride adsorption at the $\alpha-\mathrm{Al}_{2} \mathrm{O}_{3}$ /aqueous solution interface. J. Colloid Interface Sci. 2006, 298, 1-5. [CrossRef]

20. Halter, W.E. Surface acidity constants of $\alpha-\mathrm{Al}_{2} \mathrm{O}_{3}$ between 25 and $70{ }^{\circ} \mathrm{C}$. Geochim. et Cosmochim. Acta 1999, 63, 3077-3085. [CrossRef]

21. Tsyntsaru, N.; Dikusar, A.; Cesiulis, H.; Celis, J.P.; Bobanova, Z.; Sidel'nikova, S.; Belevskii, S.; Yapontseva, Y.; Bersirova, O.; Kublanovskii, V. Tribological and corrosive characteristics of electrochemical coatings based on cobalt and iron superalloys. Powder Metall. Met. Ceram. 2009, 48, 419-428. [CrossRef]

22. Huang, P.-C.; Hou, K.-H.; Sheu, H.-H.; Ger, M.-D.; Wang, G.-L. Wear properties of Ni-Mo coatings produced by pulse electroforming. Surf. Coat. Technol. 2014, 258, 639-645. [CrossRef]

23. Narasimman, P.; Pushpavanam, M.; Periasamy, V.M. Wear and scratch resistance characteristics of electrodeposited nickel-nano and micro SiC composites. Wear 2012, 292-293, 197-206. [CrossRef]

24. Eslami, M.; Saghafian, H.; Golestani-fard, F.; Robin, A. Effect of electrodeposition conditions on the properties of $\mathrm{Cu}-\mathrm{Si}_{3} \mathrm{~N}_{4}$ composite coatings. Appl. Surf. Sci. 2014, 300, 129-140. [CrossRef]

25. Nava, D.; Dávalos, C.; Martínez-Hernández, A.; Manríquez, F.; Meas, Y.; Ortega-Borges, R.; Pérez-Bueno, J.; Trejo, G. Effects of heat treatment on the tribological and corrosion properties of electrodeposited Ni-P alloys. Int. J. Electrochem. Sci. 2013, 8, 2670-2681.

26. Jeong, D.; Gonzalez, F.; Palumbo, G.; Aust, K.; Erb, U. The effect of grain size on the wear properties of electrodeposited nanocrystalline nickel coatings. Scr. Mater. 2001, 44, 493-499. [CrossRef]

27. Eslami, M.; Golestani-fard, F.; Saghafian, H.; Robin, A. Study on tribological behavior of electrodeposited Cu-Si3N4 composite coatings. Mater. Des. 2014, 58, 557-569. [CrossRef] 
28. Feng, Q.; Li, T.; Yue, H.; Qi, K.; Bai, F.; Jin, J. Preparation and characterization of nickel nano- $\mathrm{Al}_{2} \mathrm{O}_{3}$ composite coatings by sediment co-deposition. Appl. Surf. Sci. 2008, 254, 2262-2268. [CrossRef]

29. Robin, A.; Fratari, R.Q. Deposition and characterization of nickel-niobium composite electrocoatings. J. Appl. Electrochem. 2007, 37, 805-812. [CrossRef]

30. Susan, D.; Barmak, K.; Marder, A. Electrodeposited NiAl particle composite coatings. Thin Solid Film. 1997, 307, 133-140. [CrossRef]

31. Archard, J. Contact and rubbing of flat surfaces. J. Appl. Phys. 1953, 24, 981-988. [CrossRef]

32. Walsh, F.C.; Ponce de León, C.; Kerr, C.; Court, S.; Barker, B.D. Electrochemical characterisation of the porosity and corrosion resistance of electrochemically deposited metal coatings. Surf. Coat. Technol. 2008, 202, 5092-5102. [CrossRef]

33. Kongstein, O.E.; Haarberg, G.M.; Thonstad, J. Current efficiency and kinetics of cobalt electrodeposition in acid chloride solutions. Part I: The influence of current density, $\mathrm{pH}$ and temperature. J. Appl. Electrochem. 2007, 37, 669-674. [CrossRef]

34. Hunter, R.J. Zeta Potential in Colloid Science: Principles and Applications; Academic Press: Cambridge, MA, USA, 2013.

35. Bakhit, B.; Akbari, A. Synthesis and characterization of $\mathrm{Ni}-\mathrm{Co} / \mathrm{SiC}$ nanocomposite coatings using sediment co-deposition technique. J. Alloy. Compd. 2013, 560, 92-104. [CrossRef]

36. Tripathi, M.K.; Singh, D.; Singh, V. Electrodeposition of Ni-Fe/BN nano-composite coatings from a non-aqueous bath and their characterization. Int. J. Electrochem. Sci. 2013, 8, 3454-3471.

37. Wang, H.-T.; Sheu, H.-H.; Ger, M.-D.; Hou, K.-H. The effect of heat treatment on the microstructure and mechanical properties of electrodeposited nanocrystalline $\mathrm{Ni}-\mathrm{W} /$ diamond composite coatings. Surf. Coat. Technol. 2014, 259, 268-273. [CrossRef]

38. Czerwinski, F.; Szpunar, J. Controlling the thermal stability of texture in single-phase electrodeposits. Nanostruct. Mater. 1999, 11, 669-676. [CrossRef]

39. Cai, F.; Jiang, C.; Wu, X. X-ray diffraction characterization of electrodeposited Ni-Al composite coatings prepared at different current densities. J. Alloy. Compd. 2014, 604, 292-297. [CrossRef]

40. Bercot, P.; Pena-Munoz, E.; Pagetti, J. Electrolytic composite Ni-PTFE coatings: An adaptation of Guglielmi's model for the phenomena of incorporation. Surf. Coat. Technol. 2002, 157, 282-289. [CrossRef]

41. Bahadormanesh, B.; Dolati, A. The kinetics of Ni-Co/SiC composite coatings electrodeposition. J. Alloy. Compd. 2010, 504, 514-518. [CrossRef]

42. Ghanbari, S.; Mahboubi, F. Corrosion resistance of electrodeposited Ni-Al composite coatings on the aluminum substrate. Mater. Des. 2011, 32, 1859-1864. [CrossRef]

43. Vereecken, P.; Shao, I.; Searson, P. Particle codeposition in nanocomposite films. J. Electrochem. Soc. 2000, 147, 2572-2575. [CrossRef]

44. Sen, R.; Das, S.; Das, K. Effect of stirring rate on the microstructure and microhardness of $\mathrm{Ni}-\mathrm{CeO}_{2}$ nanocomposite coating and investigation of the corrosion property. Surf. Coat. Technol. 2011, 205, 3847-3855. [CrossRef]

45. Buelens, C.; Celis, J.P.; Roos, J.R. Electrochemical aspects of the codeposition of gold and copper with inert particles. J. Appl. Electrochem. 1983, 13, 541-548. [CrossRef]

46. Thiemig, D.; Bund, A. Characterization of electrodeposited $\mathrm{Ni}-\mathrm{TiO}_{2}$ nanocomposite coatings. Surf. Coat. Technol. 2008, 202, 2976-2984. [CrossRef]

47. Ma, L.; Zhou, K.-C.; Li, Z.-Y.; Wei, Q.-P. Electrodeposition of Ni-Co-Fe $\mathrm{O}_{3}$ composite coatings. J. Cent. South Univ. Technol. 2010, 17, 708-714. [CrossRef]

(C) 2020 by the authors. Licensee MDPI, Basel, Switzerland. This article is an open access article distributed under the terms and conditions of the Creative Commons Attribution (CC BY) license (http://creativecommons.org/licenses/by/4.0/). 